\title{
Radiotherapy plus temozolomide in elderly patients with glioblastoma: a "real-life" report
}

J. Biau ${ }^{1,2^{*}}$ (D) E. Chautard ${ }^{1,2}$, E. De Schlichting ${ }^{3}$, G. Dupic $^{1}$, B. Pereira ${ }^{4}$, A. Fogli ${ }^{5}$, M. Müller-Barthélémy ${ }^{2}$, P. Dalloz ${ }^{6}$, T. Khali ${ }^{3}$, A. F. Dillies ${ }^{6}$, X. Durando ${ }^{2,6}$, C. Godfraind ${ }^{2,7}$ and P. Verrelle $e^{1,8}$

\begin{abstract}
Background: The optimization of the management for elderly glioblastoma patients is crucial given the demographics of aging in many countries. We report the outcomes for a "real-life" patient cohort (i.e. unselected) comprising consecutive glioblastoma patients aged 70 years or more, treated with different radiotherapy $+/$ - temozolomide regimens.

Methods: From 2003 to 2016, 104 patients $\geq 70$ years of age, consecutively treated by radiotherapy for glioblastoma, were included in this study. All patients were diagnosed with IDH-wild type glioblastoma according to pathological criteria.

Results: Our patient cohort comprised 51 female patients (49\%) and 53 male. The median cohort age was 75 years (70-88), and the median Karnofsky performance status (KPS) was 70 (30-100). Five (5\%) patients underwent macroscopic complete resection, 9 (9\%) had partial resection, and 90 (86\%), a stereotactic biopsy. The MGMT promoter was methylated in 33/73 cases (45\%). Fifty-two (50\%), 38 (36\%), and $14(14 \%)$ patients were categorized with RPA scores of III, IV, and I-II. Thirty-three (32\%) patients received normofractionated radiotherapy (60 Gy, 30 sessions) with temozolomide (Stupp), 37 (35\%) received hypofractionated radiotherapy (median dose 40 Gy, 15 sessions) with temozolomide (HFRT + TMZ), and 34 (33\%) HFRT alone. Patients receiving only HFRT were significantly older, with lower KPSs. The median overall survival (OS; all patients) was 5.2 months. OS rates at 12, 18, and 24 months, were 19\%, $12 \%$, and 5\%, respectively, with no statistical differences between patients receiving Stupp or HFRT + TMZ $(P=0.22)$. In contrast, patients receiving HFRT alone manifested a significantly shorter survival time (3.9 months vs. 5.9 months, $P=0$. 018). In multivariate analyses, the prognostic factors for OS were: i) the type of surgery (HR: $0.47[0.26-0.86], P=0.014$ ), ii) RPA class (HR: 2.15 [1.17-3.95], $P=0.014$ ), and iii) temozolomide use irrespective of radiotherapy schedule (HR: 0.54 [0.33-0.88], $P<0.02$ ). MGMT promoter methylation was neither a prognostic nor a predictive factor.
\end{abstract}

Conclusions: These outcomes agree with the literature in terms of optimal surgery and the use of HFRT as a standard treatment for elderly GBM patients. Our study emphasizes the potential benefit of using temozolomide with radiotherapy in a real-life cohort of elderly GBM patients, irrespective of their MGMT status.

Keywords: Elderly, Glioblatoma, Temozolomide, Hypofractionated radiotherapy

\footnotetext{
*Correspondence: Julian.biau@clermont.unicancer.fr

${ }^{1}$ Radiotherapy Department, Université Clermont Auvergne, Centre Jean

Perrin, 63011 Clermont-Ferrand, France

2Université Clermont Auvergne, INSERM, U1240 IMoST, F-63000 Clermont

Ferrand, France

Full list of author information is available at the end of the article
} International License (http://creativecommons.org/licenses/by/4.0/), which permits unrestricted use, distribution, and reproduction in any medium, provided you give appropriate credit to the original author(s) and the source, provide a link to the Creative Commons license, and indicate if changes were made. The Creative Commons Public Domain Dedication waiver (http://creativecommons.org/publicdomain/zero/1.0/) applies to the data made available in this article, unless otherwise stated. 


\section{Background}

Glioblastoma (GBM) is the most common adult primary brain tumor [1]. According to the World Health Organization (WHO) classification, now updated to include molecular features such as Isocitrate DeHydrogenase (IDH) mutation, GBM is the most malignant astrocytic tumor (Grade IV) [2]. The incidence of GBM increases with age, with approximately half of all GBM patients aged over 65 years, and 20\% older than 75 years [3].

Improved diagnoses due to the standard use of noninvasive techniques (e.g. MRI), combined with stereotactic biopsy, explain, in part, the increasing incidence of GBM diagnosed in elderly patients [4]. Optimized management for this patient group is fast becoming a significant consideration, especially given the current demographic scenario of increasingly aged populations in Western nations. However, an obstacle in analyzing patient care for this cohort is its heterogeneity, which can complicate the identification of patients who could genuinely benefit from standard treatment.

For elderly patients with GBM, their median survival is drastically reduced compared to their younger counterparts [5-14]. This low median survival could be explained, in part, by an unfavorable tumor biology, a trend towards less aggressive treatment, treatment toxicity, performance status, and comorbidities $[15,16]$. Because of their poor prognoses, treatment efficiency and quality of life are of major interest in the management of these patients.

Radiotherapy results in a modest improvement in survival compared to supportive care alone in GBM patients aged 70 years or more with a good performance status, and does not reduce the quality of life or cognition [5]. Due to their poor prognosis, the time taken for normofractionated radiotherapy could constitute a third of the life expectancy for this patient group. Further, Roa et al. [6] showed that normofractionated radiotherapy (60 Gy, 30 sessions) failed to improve survival compared to hypofractionated radiotherapy (HFRT; 40 Gy, 15 sessions) in GBM patients aged 60 years or more. Further, no increased toxicity was noted with HFRT [9]. Other treatments such as chemotherapy alone, gave favorable results compared to radiotherapy, notably for elderly patients with MGMT methylation [7, 8]. The use of temozolomide (TMZ) treatment alongside radiotherapy and adjuvant TMZ, which is the standard treatment for younger patients $[17,18]$, has been debated at length for elderly GBM patients $[10,13,19,20]$. The recent results of a large phase 3 trial appeared to emphasize the role of TMZ with HFRT, especially for patients aged over 70 [14].

Although radiotherapy +/- TMZ has shown potential benefits in the management of elderly GBM patients in randomized trials $[5-8,14]$, the ability to evaluate its benefit in routine clinical practice may be limited by the selective patient populations that participate in trials (reflecting trial eligibility criteria), as well as patient sample sizes, and reporting bias [20-22]. Thus, the aim of our study was to report the outcomes of elderly GBM IDH-wild-type patients aged 70 years or more, treated consecutively with different radiotherapy +/- TMZ regimens in a single institution. Critically, this study reports data for a real-life, unselected, elderly patient population.

\section{Methods \\ Patient selection}

From February 2003 to June 2016, 104 patients aged 70 years or more, consecutively treated by radiotherapy for a GBM in Centre Jean Perrin, were included in this study. For all patients a surgery (stereotactic biopsy, partial or complete resection) permitted a histopathological analysis of the tumor to establish a GBM diagnosis without IDH mutation (by immunohistochemistry).

\section{Radiotherapy}

For irradiation, all patients were immobilized with custom thermoplastic masks. Target volume and organs at risk delineation was performed by a dedicated CT-scan in the treatment position matched and fused with contrast enhanced T1-weighted and Flair MRI sequences. The gross tumor volume (GTV) was defined as the contrast enhancement area in the T1-weighted MRI sequence and/or CT-scan, including the tumor bed for patients with partial or complete resection. The clinical target volume (CTV) was defined as the addition of a geometric tridimensional one- $\mathrm{cm}$ margin around the GTV that was corrected to the anatomical borders [2325]. The CTV also included the hyper intensity in the Flair MRI sequence. The planning target volume (PTV) was defined as the addition of a geometric tridimensional 4-mm margin around the CTV. Radiotherapy was administrated according to a Stupp normofractionated regimen of $60 \mathrm{~Gy}$ in 30 sessions (EORTC (26981-22,981)/NCIC CTG (CE.3)) [17], or according to a hypofractionated regimen (HFRT, 30-45 Gy in 10 to 15 sessions). For patients receiving concomitant chemotherapy, TMZ was administrated at a dose of $75 \mathrm{mg} / \mathrm{m}^{2}$ daily (7 days a week, from the first to last radiotherapy session). For patients receiving adjuvant chemotherapy, the TMZ dose ranged from 150 to $200 \mathrm{mg} / \mathrm{m}^{2}$ per day, given on five consecutive days per month.

\section{MGMT methylation analysis}

For 73/104 (70\%) tumor DNA samples, MGMT methylation was analyzed using the PyroMark MGMT kit (Qiagen). Chemically methylated and unmethylated human genomic DNA controls (EpiTect PCR Control DNA Set, Qiagen) were included in each batch. In brief, $40 \mathrm{ng}$ of tumor DNAs were extracted from paraffin-embedded 
tissue blocks using the FFPE DNA Extraction Kit (Zymo Research, Orange, CA). DNAs were then bisulfitemodified using the EZ DNA methylation kit (Zymo Research, Orange, CA) according to the manufacturer's recommendations. The $\mathrm{CpG}$ pyrosequencing methylation assay using the Qiagen kit was performed on a PSQ 96 MA system (Qiagen) according to the manufacturer's protocol. The PyroMark MGMT kit quantifies the level of methylation at five individual CpG sites within exon 1 of MGMT using the Pyromark CpG software (Qiagen). The $M G M T$ promoter was defined as unmethylated when the mean methylation of the five CpG sites was $<8 \%$, and methylated when this value was $\geq 8 \%$ [26].

\section{Statistical analyses}

Statistical analyses were performed using R v2.15.1 (http:// www.cran.r-project.org). Tests were two-sided, with a type I error set at $\alpha=0.05$. Baseline characteristics are presented as median values [interquartile range] for each independent group for continuous data, and as the number of patients and the associated percentages for categorical parameters. Quantitative variables (age, KPS) were categorized according to clinical relevance. Categorical variables were compared between groups (Stupp, HFRT + TMZ, HFRT) using the Chi-squared or Fisher's exact tests, followed, as appropriate $(P$-value $<0.05)$, by post-hoc tests for multiple comparisons (Marascuilo approach). For quantitative parameters, ANOVA and Kruskal-Wallis (KW) tests were performed according to ANOVA assumptions (normality verified by the Shapiro-Wilk test and homoscedasticity by the Bartlett test). If the P-value was $<0.05$, a post-hoc test was considered: Tukey-Kramer post ANOVA, or Dunn after KW. OS was defined as the interval from surgery to death, regardless of the cause of death. OS curves and estimates were constructed using the Kaplan-Meier method. To test the prognostic value of the patients' characteristics in the univariate context, OS curves were compared between groups using Cox proportional hazards regression. Finally, to evaluate the impact of treatment (Stupp, HFRT + TMZ, HFRT) on OS, multivariate analyses were performed using Cox proportional hazards regression to take into account adjustment for possible confounding factors as determined by univariate analysis and clinical relevance. Two multivariate models were constructed: model 1 with KPS, age, surgery (complete or partial resection vs biopsy only) and gender, and model 2 with RPA class and gender. Results are expressed as hazard ratios (HRs) with 95\% confidence intervals $(95 \%$-CIs).

\section{Results}

\section{Patient characteristics and treatment}

The characteristics of the 104 IDH-wild-type GBM patients are summarized in Table 1 . The median age was
75 years (range, $70-88$ years), with 51 female patients (49\%), and 53 male (51\%). The median Karnofsky performance status (KPS) was 70 (range, 30-100). According to Scott et al., the patients were then classified by their RPA (recursive partitioning analysis) class, specific for elderly patients [27]. RPA classes I and II were pooled to present data. Fifty-two patients (50\%), 38 $(36 \%)$, and $14(14 \%)$, were categorized as RPA class III, IV, and I-II, respectively. A macroscopic complete resection was realized for 5 patients (5\%), 9 patients (9\%) underwent partial resection, and 90 patients (86\%) underwent stereotactic biopsy. MGMT promoter methylation was assessed in 73/104 cases (70\%), with methylation confirmed in 33 cases (45\%); the remaining 40 cases were unmethylated (55\%).

All of the patients received radiotherapy. Thirty-three patients (32\%) adhered to a normofractionated schedule (60 Gy, 30 sessions) with TMZ used according to the Stupp protocol. Thirty-seven patients (35\%) received HFRT with TMZ (HFRT + TMZ), and 34 patients (33\%) received HFRT alone (HFRT). The HFRT regimen ranged from 30 to 45 Gy in 10 to 15 sessions (median 40 Gy in 15 fractions). Adjuvant TMZ was used for 28 patients $(27 \%)$ with a median number of cycles of 4 (range, 1-12). Patients receiving the Stupp protocol or HFRT + TMZ showed no statistical differences in terms of age, KPS, type of surgery, MGMT status, RPA class, and adjuvant TMZ treatment (Table 1). In contrast, patients receiving HFRT alone were significantly older, with a lower KPS (median of 60), and had received less adjuvant treatment.

\section{Overall survival and prognostic factors}

For the entire patient population, the median overall survival (OS) was 5.2 months (Table 2). The OS rates at 12 , 18 , and 24 months were $19 \%, 12 \%$, and $5 \%$, respectively. No statistically significant differences were found between the Stupp protocol and HFRT + TMZ $(P=0.22)$. In contrast, patients receiving HFRT alone manifested a significantly shorter survival time (3.9 months vs. 5.9 months, $P<0.05)$ (Fig. 1).

In the univariate analyses (Table 2), the prognostic factors of OS were: KPS ( $<70$ vs. $\geq 70$; median survival of 3.2 vs. 7.8 months; $P<0.01)$, the type of surgery (biopsy vs. partial or complete resection; median survival of 4.8 vs. 13.5 months; $P<0.05$ ), RPA class (median survival of 13.5 months for class I-II vs. 5.5 months for class III $(P<0.05)$ or 3.1 months for class IV $(P<0.001))$, and the use of TMZ irrespective of radiotherapy schedule (median survival of 3.9 months vs. 5.9 months, $\mathrm{P}<0.05)$. Age and gender were not statistically significant prognostic factors. MGMT status has no impact on overall survival on the entire cohort 
Table 1 Patient characteristics

\begin{tabular}{|c|c|c|c|c|c|}
\hline & & Treatment & & & \\
\hline & Total & Stupp & HFRT + TMZ & HFRT & $p$ \\
\hline Number of patients & 104 & $33(32 \%)$ & 37 (35\%) & $34(33 \%)$ & \\
\hline Gender & & & & & 0.65 \\
\hline Male & $53(51 \%)$ & $19(58 \%)$ & $18(49 \%)$ & $16(47 \%)$ & \\
\hline Female & $51(49 \%)$ & $14(42 \%)$ & 19 (51\%) & $18(53 \%)$ & \\
\hline Age & & & & & $<0.01^{*}$ \\
\hline Median (years) & 75 [70-88] & $73[70-81]$ & 75 [70-80] & 79 [70-88] & \\
\hline$<75.5$ years & $55(53 \%)$ & $24(73 \%)$ & $20(54 \%)$ & $11(32 \%)$ & \\
\hline$\geq 75.5$ years & 49 (47\%) & $9(27 \%)$ & $17(46 \%)$ & $23(68 \%)$ & \\
\hline KPS & & & & & $<0.01^{*}$ \\
\hline Median & 70 [30-100] & $80[50-100]$ & $70[30-100]$ & 60 [40-90] & \\
\hline$K P S<70$ & $40(38 \%)$ & $5(15 \%)$ & $13(35 \%)$ & $22(65 \%)$ & \\
\hline$K P S \geq 70$ & $64(62 \%)$ & $28(85 \%)$ & $24(65 \%)$ & $12(35 \%)$ & \\
\hline Type of suregery & & & & & 0.09 \\
\hline Resection (complete/ partial) & $5 / 9(5 \% / 9 \%)$ & $2 / 6(6 \%$ / 18\%) & $1 / 2(3 \% / 5 \%)$ & $2 / 1(6 \% / 3 \%)$ & \\
\hline Biopsy & $90(86 \%)$ & $25(76 \%)$ & $34(92 \%)$ & $31(91 \%)$ & \\
\hline MGMT status & & & & & 0.58 \\
\hline Methylated & $33(45 \%)$ & $11(41 \%)$ & $12(43 \%)$ & $10(56 \%)$ & \\
\hline Unmethylated & $40(55 \%)$ & $16(59 \%)$ & $16(57 \%)$ & $8(44 \%)$ & \\
\hline Unknown & 31 & 6 & 9 & 16 & \\
\hline RPA Class & & & & & $<0.001^{*}$ \\
\hline $\mid-H$ & $14(14 \%)$ & $8(24 \%)$ & $3(8 \%)$ & $3(9 \%)$ & \\
\hline III & $52(50 \%)$ & $20(61 \%)$ & $22(59 \%)$ & $10(29 \%)$ & \\
\hline IV & $38(36 \%)$ & $5(15 \%)$ & $12(32 \%)$ & $21(62 \%)$ & \\
\hline Adjuvant Temozolomide & $28(27 \%)$ & $18(55 \%)$ & $10(10 \%)$ & $0(0 \%)$ & $<0.0001^{*}$ \\
\hline Treatment at recurrence & $12(12 \%)$ & $7(21 \%)$ & $3(8 \%)$ & $2(6 \%)$ & 0.1 \\
\hline
\end{tabular}

Abbreviations: HFRT Hypofractionated Radiotherapy, TMZ Temozolomide, KPS Karnofsky Performance. *: significant difference between HFRT and Stupp/HFRT + TMZ. No statistical difference was found between Stupp and HFRT + TMZ regarding all characteristics

(prognostic factor) and on the TMZ-treated population (predictive factor).

Two models were constructed for the multivariable analysis to evaluate the use of TMZ, regardless of radiotherapy schedule: model 1 adjusted for age, gender, KPS, and type of surgery (complete or partial resection vs biopsy only); and model 2 adjusted for gender, and RPA class. In both multivariate models, the use of TMZ irrespective of radiotherapy schedule was a prognostic factor of OS (HR: 0.54 [0.33-0.88], $P<0.05$ ). The type of surgery (HR: $0.47[0.26-0.86], P<0.05)$ and RPA class (HR: 2.15 [1.17-3.95], P $<0.05$ for RPA class III; HR: 2.87 [1.53-5.41], $P<0.01$ for RPA class IV) remained prognostic factors of OS in their respective multivariate models.

\section{Discussion}

In our study we selected GBM IDH-wild-type patients aged 70 years or more, according to the new WHO classification [2], who were treated consecutively with radiotherapy. The median overall survival in our study of 5.2 months agrees with other studies of elderly GBM patients [5-10, 12]. Roa et al. [6], in their assessment of the impact of radiotherapy regimens, found a similar median survival when using normofractionated radiotherapy (5.1 months) and HFRT (5.6 months). Three recent population-based studies of 1652, 5252, and 5575 elderly GBM patients reported median survivals of between 5 and 7.4 months, depending on the type of treatment $[10,12,20]$. As previously reported, our study shows that a KPS score $<70$ is associated with a poorer prognosis (median survival: 3.2 months), underlining the need to consider an active therapy on a case-by-case basis.

Our study suggests improved survival with partial or complete surgical resection compared to biopsy, as reported by others in retrospective studies in elderly GBM patients $[28,29]$. Caution should be used when interpreting these data as only 14 patients had complete or partial resection vs 90 biopsy only. Furthermore, biopsy 
Table 2 Survival and prognostic factors

\begin{tabular}{|c|c|c|c|c|c|c|}
\hline & \multirow{2}{*}{$\begin{array}{l}\text { Median } \\
\text { survival } \\
\text { (months) }\end{array}$} & \multirow{2}{*}{$\begin{array}{l}12 \text { months } \\
\text { survival (\%) }\end{array}$} & \multicolumn{2}{|c|}{$\underline{\text { Univariate analysis }}$} & \multicolumn{2}{|c|}{$\underline{\text { Multivariate analysis }}$} \\
\hline & & & $\mathrm{HR}[95 \% \mathrm{Cl}]$ & $p$ & $\mathrm{HR}[95 \% \mathrm{Cl}]$ & $p$ \\
\hline \multicolumn{7}{|l|}{ Age } \\
\hline$<75.5$ years & 5.6 & 18.6 & & & & \\
\hline$\geq 75.5$ years & 5.1 & 17.8 & 1.03 [0.69-1.53] & 0.88 & $0.76[0.49-1.20]$ & 0.25 \# \$ \\
\hline \multicolumn{7}{|l|}{ KPS } \\
\hline$<70$ & 3.2 & 7.5 & & & & \\
\hline$\geq 70$ & 7.8 & 25 & $0.52[0.34-0.77]$ & $<0.01$ & 0.70 [0.45-1.09] & $0.11^{\#}$ \\
\hline \multicolumn{7}{|l|}{ Gender } \\
\hline Female & 4.5 & 15.7 & & & & \\
\hline Male & 6.1 & 20.7 & $0.70[0.47-1.05]$ & 0.08 & $0.71[0.47-1.08]$ & $0.10^{\# \text { \$ }}$ \\
\hline \multicolumn{7}{|l|}{ MGMT status } \\
\hline Methylated & 5.9 & 12.1 & & & & \\
\hline Unmethylated & 4.8 & 17.5 & $1.14[0.72-1.82]$ & 0.57 & & \\
\hline \multicolumn{7}{|l|}{ Type of surgery } \\
\hline Biopsy & 4.8 & 50 & & & & \\
\hline Resection & 13.5 & 13 & $0.43[0.24-0.77]$ & $<0.05$ & $0.47[0.26-0.86]$ & $<0.05^{\#}$ \\
\hline \multicolumn{7}{|l|}{ RPA class } \\
\hline$H-1 \mid$ & 13.5 & 50 & & & & \\
\hline III & 5.5 & 15.4 & $1.95[1.07-3.57]$ & $<0.05 *$ & 2.15 [1.17-3.95] & $<0.05^{\$ *}$ \\
\hline IV & 3.1 & 7.9 & $3.08[1.65-5.76]$ & $<0.001 *$ & $2.87[1.53-5.41]$ & $<0.01^{\$ *}$ \\
\hline \multicolumn{7}{|l|}{ Type of treatment } \\
\hline$H F R T+T M Z$ & 5.5 & 18.9 & & & & \\
\hline Stupp & 9.6 & 24.2 & $0.74[0.46-1.20]$ & $0.22^{\alpha}$ & & \\
\hline HFRT & 3.9 & 8.8 & & & & \\
\hline HFRT + TMZ or Stupp & 5.9 & 22.9 & $0.6[0.40-0.92]$ & $<0.05^{\S}$ & $0.54[0.33-0.88]$ & $<0.05^{\# \text { \$ }}$ \\
\hline
\end{tabular}

Abbreviations: HR hazard ratio, HFRT Hypofractionated radiotherapy, TMZ Temozolomide, KPS Karnofsky Performance Status. \#: Multivariate analysis model 1 adjusted for age, gender, KPS and type of surgery, \$: Multivariate analysis model 2 adjusted for gender, and RPA class.* compared with RPA class I-II. a compared with HFRT+TMZ; §: compared with HFRT

is ordinarily offered to patients unsuitable for partial or complete surgery. Only one prospective study by Vuorinen et al. evaluated the impact of surgery in elderly patients [30].With a reduced cohort, they reported an improvement of median survival after surgical resection (5.6 months) compared to biopsy (2.8 months). A prospective randomized multicentric study (CSA NCT02892708) is ongoing in operable patients over 70 years of age, and will compare surgical resection and biopsy.

Another interesting aspect of these data concerns the type of radiotherapy fractionation. We found no survival differences when comparing patients treated with HFRT + TMZ vs the Stupp regimen. These results agree with data reported by Roa et al. in a randomized trial evaluating HFRT and normofractionated radiotherapy [6]. Thus, according to the guidelines, the HFRT regimen is more than a therapeutic alternative to the normofractionated regimen for elderly patients [19]. However, this randomized trial was conducted before the era of TMZ. Recently, Lombardi et al. [11] published a large multicenter retrospective study comparing short (HFRT; 40 Gy, 15 sessions) or standard-course (60 Gy, 30 sessions) irradiation plus concomitant TMZ in elderly ( $\geq 60$ years) GBM patients (Table 3 ). Patients receiving HFRT were older $(p=0.07)$. This study suggested that standard-course irradiation + TMZ might be more effective than HFRT + TMZ. The median overall survival in this study was remarkably high with 17.3 months; with even 19.4 months for patients treated with the Stupp regimen (4.8 months more than in the original study by Stupp et al. [17]). This could maybe be explained by the relatively strict inclusion criteria in this retrospective study with no patients with biopsy only (70-80\% of patients with complete resections) and $82 \%$ of patients ECOG 0-1, not reflecting "real life" data as in our study. Furthermore, average age in this study was 71 years while our study only included patients 70 years 

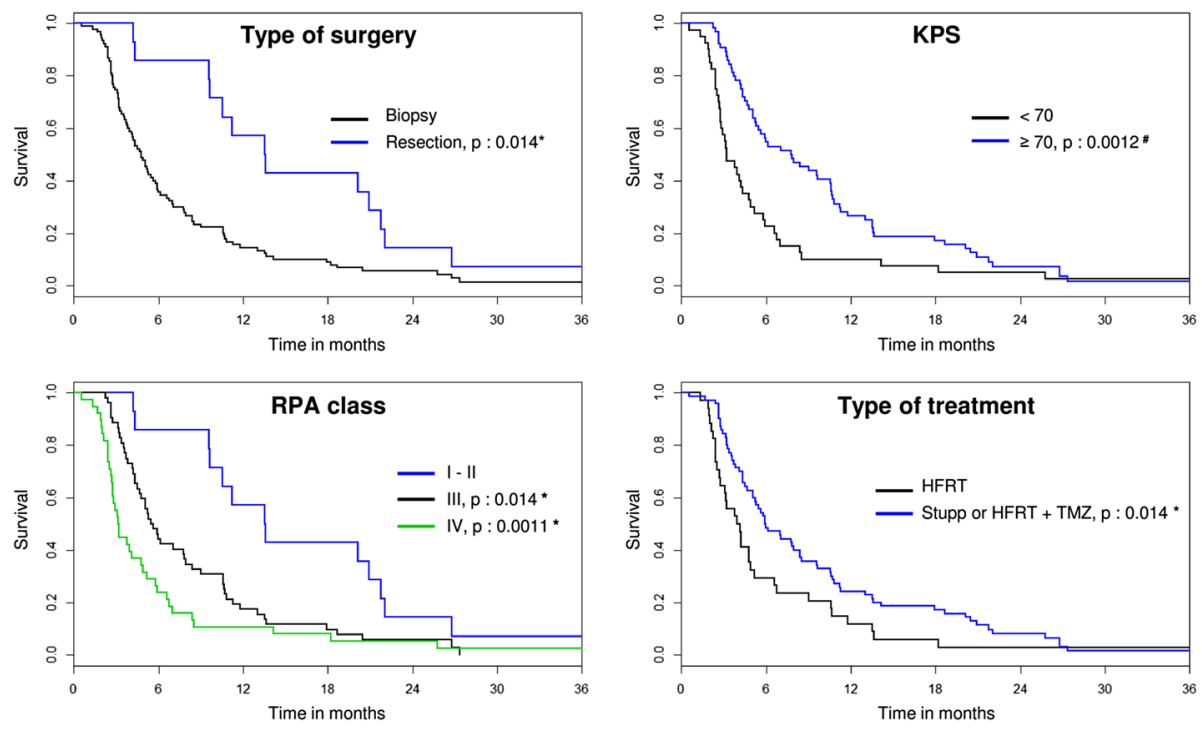

Fig. 1 Prognostic factors for elderly GBM patients. Kaplan-Meier survival curves for patients' classified according to type of surgery, Karnofsky Performance Status (KPS), RPA class, and type of treatment. The P-values of the prognostic factors are indicated for univariate $(\#)$ or multivariate $(*)$ analyses. HFRT: Hypofractionated radiotherapy, TMZ: Temozolomide

or more, with a median age of 75 years. However, this study brings interesting data concerning "moderate" elderly patients, in excellent general status, who had extensive surgery and for which a Stupp regimen might considered over HFRT + TMZ. Minniti et al. [31] also compared the outcomes of elderly ( $\geq 65$ years) GBM patients receiving either short (HFRT; 40 Gy, 15 sessions) or standard-course (60 Gy, 30 sessions) irradiation plus concomitant TMZ (Table 3). To limit the potential bias of such a retrospective study, they designed a propensity-matched analysis. Patients given standardcourse irradiation + TMZ were more likely to be younger (median age of 68 years vs 71) and to undergo total/ subtotal resection. After propensity score-matching analysis, they found no differences in overall survival or progression-free survival between both groups.

Recently, Guedes de Castro et al. [32] compared 2 short-course radiation therapy regimens in elderly (65 years or older) glioblastoma patients: 25 Gy in 5 fractions vs 40 Gy in 15 fractions. This trial was conducted before the results of Perry's trial [14] showing the superiority of combining TMZ with HFRT over HFRT alone. The short-course HFRT ( 25 Gy in 5 fractions) results were not statistically significantly different from the results of commonly used HFRT (40Gy in 15 fractions) (median overall survival of 6.8 months vs 6.2 months; $p=0.936$ ). The authors concluded that a short-course HFRT regimen of $25 \mathrm{~Gy}$ in 5 fractions was an acceptable treatment option for patients aged $\geq 65$ years, mainly those with a poor performance status or contraindication to chemotherapy.

Several studies have shown that MGMT methylation appears to be to an important prognostic factor in the management of elderly GBM patients, and a predictive factor of response to radiotherapy + TMZ [11, 13, 14]. In our study, the proportion of patients with methylated MGMT is similar to the published data. However, we failed to find that $M G M T$ methylation was either a prognostic or predictive factor. This discrepancy could, in part, be explained by our smaller cohort size and the high rate of biopsy. MGMT methylation was described as predictive of TMZ treatment response in elderly patients with a good performance status in two randomized phase III trials comparing TMZ alone with various radiotherapy regimens (Nordic trial [7] and the German trial NOA-08 [8]). However, none of our patients underwent this type of treatment.

We also report that the use of TMZ, irrespective of radiotherapy regimen, and irrespective of the MGMT promoter status, was a positive prognostic factor in multivariate analysis. A phase II clinical trial published by Minniti et al. tested HFRT + TMZ (40 Gy, 15 fractions) and adjuvant TMZ in patients aged over 70 years and with a KPS score $>60$ [33]. They reported a $22 \%$ rate of grade III-IV toxicities linked to TMZ uptake, the majority (15\%) constituting hematologic toxicity ( $4 \%$ in adjuvant TMZ). The median survival was 12.4 months. OS rates at 12 and 24 months were $58 \%$ and $20 \%$, respectively. Perry et al. published a phase III clinical trial comparing HFRT $+/-$ TMZ in patients of 65 years of age or older [14]. The median survival time increased from 7.6 months for radiotherapy alone to 9.3 months for the combined treatment $(P<0.001)$. This increased survival was more pronounced for patients aged over 70 years with a methylated $M G M T$ promoter but was also 
Table 3 Major studies regarding elderly glioblastoma patients

\begin{tabular}{|c|c|c|c|c|c|c|c|c|c|}
\hline $\begin{array}{l}\text { Major } \\
\text { interest }\end{array}$ & Reference & Year & Design & $\begin{array}{l}\text { Number } \\
\text { of } \\
\text { patients }\end{array}$ & Age & KPS & Treatment & $\begin{array}{l}\text { Median } \\
\text { survival in } \\
\text { months }(p)\end{array}$ & Notes \\
\hline \multirow[t]{2}{*}{ Surgery } & \multirow[t]{2}{*}{$\begin{array}{l}\text { Vuorien } \\
\text { et al.[30] }\end{array}$} & \multirow[t]{2}{*}{2003} & \multirow[t]{2}{*}{ Prospective } & \multirow[t]{2}{*}{23} & \multirow[t]{2}{*}{$\geq 65$} & \multirow[t]{2}{*}{$>60$} & Biopsy + RT & 2.8 & \multirow[t]{2}{*}{$\begin{array}{l}\text { Longer survival after resection while time to } \\
\text { neurological deterioration did not differ. }\end{array}$} \\
\hline & & & & & & & $\begin{array}{l}\text { Resection } \\
+ \text { RT }\end{array}$ & $\begin{array}{l}5.7 \\
(<0.05)\end{array}$ & \\
\hline \multirow[t]{4}{*}{$\begin{array}{l}\text { Radio- } \\
\text { therapy }\end{array}$} & \multirow[t]{2}{*}{$\begin{array}{l}\text { Roa } \\
\text { et al.[6] }\end{array}$} & \multirow[t]{2}{*}{2004} & \multirow[t]{2}{*}{ Prospective } & \multirow[t]{2}{*}{100} & \multirow[t]{2}{*}{$\geq 60$} & \multirow[t]{2}{*}{$\geq 50$} & RT & 5.1 & \multirow[t]{2}{*}{$\begin{array}{l}\text { Half overall treatment time for HFRT with no } \\
\text { difference in survival. }\end{array}$} \\
\hline & & & & & & & HFRT & 5.6 (ns) & \\
\hline & \multirow[t]{2}{*}{$\begin{array}{l}\text { Keime- } \\
\text { Guibert et al. } \\
{[5]}\end{array}$} & \multirow[t]{2}{*}{2010} & \multirow[t]{2}{*}{ Prospective } & \multirow[t]{2}{*}{81} & \multirow[t]{2}{*}{$\geq 70$} & $\geq 70$ & $\begin{array}{l}\text { Supportive } \\
\text { care }\end{array}$ & 3.9 & \multirow[t]{2}{*}{ No negative effect of RT on quality of life. } \\
\hline & & & & & & & RT & $\begin{array}{l}6.7 \\
(<0.01)\end{array}$ & \\
\hline \multirow{11}{*}{$\begin{array}{l}\text { Radio- } \\
\text { therapy } \\
+ \text { TMZ }\end{array}$} & \multirow{4}{*}{$\begin{array}{ll} & \text { Minniti } \\
\text { oy } & \text { et al. [34] } \\
\text { Minniti } \\
\text { et al. [33] }\end{array}$} & 2009 & Prospective & 43 & $\geq 70$ & $\geq 60$ & HFRT + TMZ & 9.3 & $\begin{array}{l}\text { Grade } 3-4 \text { hematologic toxicity occurred in } 28 \% \\
\text { of patients. no negative effect on quality of life. }\end{array}$ \\
\hline & & 2012 & Prospective & 71 & $>70$ & $>60$ & $\begin{array}{l}\text { HFRT }+ \text { TMZ } \\
\text { and TMZ }\end{array}$ & 12.4 & $\begin{array}{l}\text { Grade } 3-4 \text { hematologic toxicity occurred in } 15 \% \\
\text { of patients. }\end{array}$ \\
\hline & & \multirow[t]{2}{*}{2015} & \multirow[t]{2}{*}{ Retrospecitve } & \multirow[t]{2}{*}{127} & \multirow[t]{2}{*}{$\geq 65$} & \multirow[t]{2}{*}{$\geq 60$} & $\begin{array}{l}R T+T M Z \\
\text { and TMZ }\end{array}$ & 12 & \multirow[t]{2}{*}{$\begin{array}{l}\text { No difference in overall survival or progression } \\
\text { free survival between standard RT and HFRT }\end{array}$} \\
\hline & & & & & & & $\begin{array}{l}\text { HFRT }+ \text { TMZ } \\
\text { and TMZ }\end{array}$ & 12.5 (ns) & \\
\hline & \multirow[t]{2}{*}{$\begin{array}{l}\text { Lombardi } \\
\text { et al. [11] }\end{array}$} & 2015 & Retrospecitve & 237 & $\geq 65$ & $\begin{array}{l}\text { ECOG } \\
\text { PS } 0-2\end{array}$ & HFRT + TMZ & 13.8 & $\begin{array}{l}\text { Potential advantage of standard RT over HFRT } \\
\text { for "moderate" elderly patients with good clinical }\end{array}$ \\
\hline & & & & & & & $R T+T M Z$ & $\begin{array}{l}19.4 \\
(p=0.02)\end{array}$ & status and extensive surgery \\
\hline & $\begin{array}{l}\text { Perry } \\
\text { et al.[14] }\end{array}$ & 2017 & Prospective & 562 & $\geq 65$ & $\begin{array}{l}\text { ECOG } \\
\text { PS } 0-2\end{array}$ & HFRT & 7.6 & $\begin{array}{l}\text { The addition of TMZ (concomitant and adjuvant) } \\
\text { to HFRT resulted in longer overall survival than }\end{array}$ \\
\hline & & & & & & & $\begin{array}{l}\text { HFRT }+ \text { TMZ } \\
\text { and TMZ }\end{array}$ & $\begin{array}{l}9.3 \\
(p<0.001)\end{array}$ & \\
\hline & $\begin{array}{l}\text { Present } \\
\text { study }\end{array}$ & 2017 & Retrospective & 104 & $\geq 70$ & $\geq 30$ & HFRT & $\begin{array}{l}3.9 \\
(p<0.05)^{*}\end{array}$ & $\begin{array}{l}\text { Potential benefit of combining TMZ with RT in } \\
\text { an unselected cohort, irrespective of MGMT }\end{array}$ \\
\hline & & & & & & & HFRT + TMZ & 5.5 & promoter status. \\
\hline & & & & & & & $R T+T M Z$ & $9.6(n s)^{* *}$ & \\
\hline $\begin{array}{l}\text { HFRT } \\
\text { alone }\end{array}$ & $\begin{array}{l}\text { Guedes } \\
\text { de Castro } \\
\text { et al. [32] }\end{array}$ & 2017 & Prospective & 61 & $\geq 65$ & $\geq 50$ & $\begin{array}{l}\text { HFRT 40Gy in } \\
15 \text { fractions }\end{array}$ & 6.2 & $\begin{array}{l}\text { HFRT of 25Gy in } 5 \text { fractions seemed acceptable } \\
\text { especially for elderly patients with a poor } \\
\text { performance status or contraindication to }\end{array}$ \\
\hline & & & & & & & $\begin{array}{l}\text { HFRT 25Gy in } \\
5 \text { fractions }\end{array}$ & 9.1 & \\
\hline $\begin{array}{l}\text { TMZ } \\
\text { alone }\end{array}$ & $\begin{array}{l}\text { Wick } \\
\text { et al. [8] }\end{array}$ & 2012 & Prospective & 371 & $>65$ & $\geq 60$ & $\begin{array}{l}\text { Dose-dense } \\
\text { TMZ alone }\end{array}$ & 8.0 & $\begin{array}{l}\text { MGMT methylation is a predictive marker of TMZ } \\
\text { alone efficacy. }\end{array}$ \\
\hline & & & & & & & RT & 9.6 (ns) & \\
\hline & $\begin{array}{l}\text { Malmström } \\
\text { et al. [7] }\end{array}$ & 2012 & Prospective & 291 & $\geq 60$ & $\begin{array}{l}\text { OMS } \\
0-2\end{array}$ & TMZ alone & 8 & $\begin{array}{l}\text { No benefit of RT over HFRT. MGMT methylation } \\
\text { is a predictive marker of TMZ alone efficacy. }\end{array}$ \\
\hline & & & & & & & HFRT & 7.5 & \\
\hline & & & & & & & RT & 6 & \\
\hline $\begin{array}{l}\text { Poor } \\
\text { perfor- } \\
\text { mance }\end{array}$ & $\begin{array}{l}\text { Gállego } \\
\text { Pérez-Larraya } \\
\text { et al. [35] }\end{array}$ & 2011 & Prospective & 70 & $\geq 70$ & $<70$ & TMZ alone & 5.8 & $\begin{array}{l}\text { KPS improvement in } 30 \% \text { of patients by } 10 \text { or } \\
\text { more points. }\end{array}$ \\
\hline Status & $\begin{array}{l}\text { Reyes-Botero } \\
\text { et al. [36] }\end{array}$ & 2013 & Prospective & 66 & $\geq 70$ & $<70$ & $\begin{array}{l}\text { TMZ }+ \\
\text { Bevacizumab }\end{array}$ & 5.5 & $\begin{array}{l}\text { Lower safety of the combination of TMZ with } \\
\text { bevacizumab, no survival benefit }\end{array}$ \\
\hline
\end{tabular}


present for unmethylated MGMT promoter. In our study, the median survival of patients treated by HFRT + TMZ was 5.5 months with 1 -year OS rate of $19 \%$. However, our cohort demonstrated a higher rate of stereotactic biopsy (92\%) compared to either Minniti et al. (13\%) or Perry et al. (31.7\%) [14, 33].

As regards to the literature reported here, and the results of our "real life" report, HFRT + TMZ appears as a major option for elderly GBM patients, regardless of MGMT promoter status, with a favorable balance between efficacy and quality of life. For patients unsuitable for TMZ but suitable for radiotherapy, HFRT alone may still have a role. For "moderate" elderly patients, with excellent general status who underwent extensive resection and thus have a better prognosis, a Stupp regimen might be considered.

\section{Conclusions}

The outcomes reported in this study agree with the literature in terms of the use of optimal surgery as well as HFRT as a standard treatment for elderly GBM patients with KPS scores $\geq 70$. Our study underscores the potential benefits to elderly GBM patients of combining TMZ with radiotherapy in an unselected cohort, irrespective of MGMT promoter status.

\section{Abbreviations}

CTV: Clinical Target Volume; GBM: Glioblastoma; GTV: Gross Tumor Volume; HFRT: HypoFractionated RadioTherapy; IDH: Isocitrate DeHydrogenase; KPS: Karnofsky Performance Status; MGMT: O6-MethylGuanine-DNAMethylTransferase; OS: Overall Survival; PTV: Planning Target Volume; RPA: Recursive Partitioning Analysis; TMZ: Temozolomide; WHO: World Health Organization

\section{Acknowledgements}

Not applicable.

\section{Funding}

No funding was received.

\section{Availability of data and materials}

The dataset supporting the conclusions of this article contains clinical as well as demographic data that can't be shared online (restricted by the local ethical committee). However, selected data can be requested from the corresponding author.

\section{Authors' contributions}

$\mathrm{JB}$ and EC designed the study, collected and analyzed the data, wrote the manuscript and contributed equally to this work. EDS and TK (neurosurgery); JB, GD, PD and PV (Radiation oncology); AFD and XD (medical oncology) and CG (pathology) gave important intellectual imput and carefully revised the manuscript. AF and MB have done MGMT methylation experiments and carefully revised the manuscript. EC and BP have done statistical analysis. PV supervised the study and contributed to data interpretation. All authors approved the final manuscript for submission.

\section{Ethics approval and consent to participate}

Study ethics approval was obtained from CECIC Rhône-Alpes-Auvergne, Grenoble, IRB 5921. The protocol, waivers of informed consent documents and authorization are satisfactory and in compliance with national and institutional guidelines.
Consent for publication

Not applicable.

\section{Competing interests}

The authors declare that they have no competing interests.

\section{Publisher's Note}

Springer Nature remains neutral with regard to jurisdictional claims in published maps and institutional affiliations.

\section{Author details}

${ }^{1}$ Radiotherapy Department, Université Clermont Auvergne, Centre Jean Perrin, 63011 Clermont-Ferrand, France. ²Université Clermont Auvergne, INSERM, U1240 IMoST, F-63000 Clermont Ferrand, France. ${ }^{3}$ Neurosurgery Department, Clermont-Ferrand Hospital, 63003 Clermont-Ferrand, France. ${ }^{4}$ Biostatistics Department, DRCl, Clermont-Ferrand Hospital, 63003 Clermont-Ferrand, France. ${ }^{5}$ Université Clermont Auvergne, CNRS UMR 6293, INSERM U1103, GReD Laboratory, 63000 Clermont-Ferrand, France. ${ }^{6}$ Oncology Department, Université Clermont Auvergne, Centre Jean Perrin, 63011 Clermont-Ferrand, France. ${ }^{7}$ Anatomopathology Department, Clermont-Ferrand Hospital, 63003 Clermont-Ferrand, France. ${ }^{8}$ Radiation Oncology Department, Institut Curie, 75248 Paris, France.

Received: 5 July 2017 Accepted: 21 November 2017

Published online: 06 December 2017

References

1. Ricard D, Idbaih A, Ducray F, Lahutte M, Hoang-Xuan K, Delattre J-Y. Primary brain tumours in adults. Lancet. 2012:379:1984-96.

2. Louis DN, Perry A, Reifenberger G, von Deimling A, Figarella-Branger D, Cavenee WK, et al. The 2016 World Health Organization classification of tumors of the central nervous system: a summary. Acta Neuropathol (Berl). 2016:131:803-20.

3. Ostrom QT, Gittleman H, Fulop J, Liu M, Blanda R, Kromer C, et al. CBTRUS statistical report: primary brain and central nervous system tumors diagnosed in the United States in 2008-2012. Neuro-Oncol. 2015;17(Suppl 4):iv1-iv62.

4. Chakrabarti I, Cockburn M, Cozen W, Wang Y-P, Preston-Martin S. A population-based description of glioblastoma multiforme in Los Angeles County, 1974-1999. Cancer. 2005;104:2798-806.

5. Keime-Guibert F, Chinot O, Taillandier L, Cartalat-Carel S, Frenay M, Kantor G, et al. Radiotherapy for glioblastoma in the elderly. N Engl J Med. 2007:356: 1527-35.

6. Roa W, Brasher PMA, Bauman G, Anthes M, Bruera E, Chan A, et al. Abbreviated course of radiation therapy in older patients with glioblastoma multiforme: a prospective randomized clinical trial. J Clin Oncol Off J Am Soc Clin Oncol. 2004:22:1583-8.

7. Malmström A, Grønberg BH, Marosi C, Stupp R, Frappaz D, Schultz H, et al. Temozolomide versus standard 6-week radiotherapy versus hypofractionated radiotherapy in patients older than 60 years with glioblastoma: the Nordic randomised, phase 3 trial. Lancet Oncol. 2012;13: 916-26.

8. Wick W, Platten M, Meisner C, Felsberg J, Tabatabai G, Simon M, et al. Temozolomide chemotherapy alone versus radiotherapy alone for malignant astrocytoma in the elderly: the NOA-08 randomised, phase 3 trial. Lancet Oncol. 2012;13:707-15.

9. Marijnen CAM, van den Berg SMP, van Duinen SG, Voormolen JHC, Noordijk EM. Radiotherapy is effective in patients with glioblastoma multiforme with a limited prognosis and in patients above 70 years of age: a retrospective single institution analysis. Radiother. Oncol. J. Eur. Soc. Ther. Radiol Oncol. 2005;75:210-6.

10. Arvold ND, Cefalu M, Wang Y, Zigler C, Schrag D, Dominici F. Comparative effectiveness of radiotherapy with vs. without temozolomide in older patients with glioblastoma. J Neuro-Oncol. 2017:131:301-11.

11. Lombardi G, Pace A, Pasqualetti F, Rizzato S, Faedi M, Anghileri E, et al. Predictors of survival and effect of short (40 Gy) or standard-course (60 Gy) irradiation plus concomitant temozolomide in elderly patients with glioblastoma: a multicenter retrospective study of AINO (Italian Association of Neuro-Oncology). J Neuro-Oncol. 2015;125:359-67. 
12. Shah BK, Bista A, Sharma S. Survival trends in elderly patients with Glioblastoma in the United States: a population-based study. Anticancer Res. 2016;36:4883-6.

13. Franceschi E, Depenni R, Paccapelo A, Ermani M, Faedi M, Sturiale C, et al. Which elderly newly diagnosed glioblastoma patients can benefit from radiotherapy and temozolomide? A PERNO prospective study. J NeuroOncol. 2016;128:157-62.

14. Perry JR, Laperriere N, O'Callaghan CJ, Brandes AA, Menten J, Phillips C, et al. Short-course radiation plus Temozolomide in elderly patients with Glioblastoma. N Engl J Med. 2017;376:1027-37.

15. Laperriere N, Weller M, Stupp R, Perry JR, Brandes AA, Wick W, et al. Optimal management of elderly patients with glioblastoma. Cancer Treat Rev. 2013; 39:350-7.

16. Chargari C, Feuvret L, Bauduceau O, Ricard D, Cuenca X, Delattre J-Y, et al. Treatment of elderly patients with glioblastoma: from clinical evidence to molecular highlights. Cancer Treat Rev. 2012;38:988-95.

17. Stupp R, Mason WP, van den Bent MJ, Weller M, Fisher B, Taphoorn MJB, et al. Radiotherapy plus concomitant and adjuvant temozolomide for glioblastoma. N Engl J Med. 2005;352:987-96.

18. Stupp R, Hegi ME, Mason WP, van den Bent MJ, Taphoorn MJB, Janzer RC, et al. Effects of radiotherapy with concomitant and adjuvant temozolomide versus radiotherapy alone on survival in glioblastoma in a randomised phase III study: 5-year analysis of the EORTC-NCIC trial. Lancet Oncol. 2009; 10:459-66.

19. Sulman EP, Ismaila N, Armstrong TS, Tsien C, Batchelor TT, Cloughesy T, et al. Radiation therapy for Glioblastoma: American Society of Clinical Oncology clinical practice guideline endorsement of the American Society for Radiation Oncology guideline. J Clin Oncol Off J Am Soc Clin Oncol. 2017:35:361-9.

20. Huang J, Samson P, Perkins SM, Ansstas G, Chheda MG, DeWees TA, et al. Impact of concurrent chemotherapy with radiation therapy for elderly patients with newly diagnosed glioblastoma: a review of the National Cancer Data Base. J Neuro-Oncol. 2017;131:593-601.

21. Goodwin PJ, Ballman KV, Small EJ, Cannistra SA. Evaluation of treatment benefit in journal of clinical oncology. J Clin Oncol Off J Am Soc Clin Oncol. 2013;31:1123-4

22. Booth CM, Tannock IF. Randomised controlled trials and population-based observational research: partners in the evolution of medical evidence. $\mathrm{Br} J$ Cancer. 2014;110:551-5.

23. Feuvret L, Antoni D, Biau J, Truc G, Noël G, Mazeron J-J. [Guidelines for the radiotherapy of gliomas]. Cancer Radiother J Soc Francaise Radiother Oncol. 2016;20 Suppl:S69-S79.

24. McDonald MW, H-KG S, Curran WJ, Crocker IR. Pattern of failure after limited margin radiotherapy and temozolomide for glioblastoma. Int J Radiat Oncol Biol Phys. 2011;79:130-6.

25. Wernicke AG, Smith AW, Taube S, Mehta MP. Glioblastoma: radiation treatment margins, how small is large enough? Pract. Radiat Oncol. 2016;6:298-305.

26. McDonald KL, Rapkins RW, Olivier J, Zhao L, Nozue K, Lu D, et al. The T genotype of the MGMT C>T (rs16906252) enhancer single-nucleotide polymorphism (SNP) is associated with promoter methylation and longer survival in glioblastoma patients. Eur J Cancer Oxf Engl 1990. 2013;49:360-8.

27. Scott JG, Bauchet L, Fraum TJ, Nayak L, Cooper AR, Chao ST, et al. Recursive partitioning analysis of prognostic factors for glioblastoma patients aged 70 years or older. Cancer. 2012;118:5595-600.

28. Zouaoui S, Darlix A, Fabbro-Peray P, Mathieu-Daudé H, Rigau V, Fabbro M, et al. Oncological patterns of care and outcomes for 265 elderly patients with newly diagnosed glioblastoma in France. Neurosurg Rev. 2014;37:41523. discussion 423-424

29. Noorbakhsh A, Tang JA, Marcus LP, McCutcheon B, Gonda DD, Schallhorn CS, et al. Gross-total resection outcomes in an elderly population with glioblastoma: a SEER-based analysis. J Neurosurg. 2014;120:31-9.

30. Vuorinen V, Hinkka S, Färkkilä $M$, Jääskeläinen J. Debulking or biopsy of malignant glioma in elderly people - a randomised study. Acta Neurochir. 2003:145:5-10

31. Minniti G, Scaringi C, Lanzetta G, Terrenato I, Esposito V, Arcella A, et al. Standard (60 Gy) or short-course (40 Gy) irradiation plus concomitant and adjuvant temozolomide for elderly patients with glioblastoma: a propensitymatched analysis. Int J Radiat Oncol Biol Phys. 2015;91:109-15.

32. Guedes de Castro D, Matiello J, Roa W, Ghosh S, Kepka L, Kumar N, et al. Survival outcomes with short-course radiation therapy in elderly patients with Glioblastoma: data from a randomized phase 3 trial. Int J Radiat Oncol Biol Phys. 2017;98:931-8.

33. Minniti G, Lanzetta G, Scaringi C, Caporello P, Salvati M, Arcella A, et al. Phase II study of short-course radiotherapy plus concomitant and adjuvant Temozolomide in elderly patients with Glioblastoma. Int J Radiat Oncol Biol Phys. 2012;83:93-9.

34. Minniti G, De Sanctis V, Muni R, Rasio D, Lanzetta G, Bozzao A, et al. Hypofractionated radiotherapy followed by adjuvant chemotherapy with temozolomide in elderly patients with glioblastoma. J Neuro-Oncol. 2009;91: 95-100.

35. Gállego Pérez-Larraya J, Ducray F, Chinot O, Catry-Thomas I, Taillandier L, Guillamo J-S, et al. Temozolomide in elderly patients with newly diagnosed glioblastoma and poor performance status: an ANOCEF phase II trial. J Clin Oncol Off J Am Soc Clin Oncol. 2011:29:3050-5.

36. Reyes-Botero G, Honnorat J, Chinot OL, Taillandier L, Catry-Thomas I, Barriere J, et al. Temozolomide plus bevacizumab in elderly patients with newly diagnosed glioblastoma and poor performance status: an Anocef phase II trial. J Clin Oncol. 2013;31:2020.

\section{Submit your next manuscript to BioMed Central and we will help you at every step:}

- We accept pre-submission inquiries

- Our selector tool helps you to find the most relevant journal

- We provide round the clock customer support

- Convenient online submission

- Thorough peer review

- Inclusion in PubMed and all major indexing services

- Maximum visibility for your research

Submit your manuscript at www.biomedcentral.com/submit
) Biomed Central 